\title{
MHD Flow, Heat and Mass Transfer due to Axially Moving Cylinder in Presence of Thermal Diffusion, Radiation and Chemical Reactions in a Binary Fluid Mixture
}

\author{
B.R Sharma \\ Department of Mathematics, \\ Dibrugarh University, \\ Dibrugarh-786004, \\ Assam, India
}

\author{
Hemanta Konwar \\ Department of Mathematics, \\ Dibrugarh University, \\ Dibrugarh-786004, \\ Assam, India
}

\begin{abstract}
In the present paper we have studied the effects of magnetic field, thermal diffusion, thermal radiation and chemical reaction on velocity, temperature and concentration fields about an axially moving isothermal semi infinite solid vertical cylinder in two dimensional incompressible viscous binary fluid mixtures. The governing equations of continuity, momentum, energy and concentration are transformed into non similar boundary layer equations and are solved by using a regular perturbation method together with Matlab's built in solver bvp4c. Numerical solutions for axial velocity component, temperature and concentration of the rarer and lighter component of the binary fluid mixture are obtained on the basis of boundary layer approximation and presented graphically for axial curvature parameter, magnetic field parameter, thermal diffusion parameter, radiation parameter and chemical reaction parameter. It has been found that these parameters affect considerably the flow characteristics. The problem under consideration reduces to the flat plate case when the curvature parameter is absent.
\end{abstract}

\section{Keywords}

Vertical cylinder, magnetic field, thermal diffusion, radiation, chemical reaction, binary fluid mixture, MATLAB-bvp4c.

\section{INTRODUCTION}

MHD flow, heat and mass transfer in viscous binary fluid mixtures have enormous applications in many engineering problems such as MHD power generators, petroleum industries, chemical process engineering, plasma studies, geothermal energy extractions, nuclear fusion, pharmaceutical industries, the boundary layer control in the field of aerodynamics and many others. In recent years, MHD flow, heat and mass transfer about cylindrical bodies have attracted many researchers owing to the fact that cylindrical shaped bodies have been used in nuclear waste disposal, space science, energy extortion in underground and catalytic beds. The study of boundary layer flow over a continuous impermeable surface moving at a constant speed was carried out by Sakiadis [1]. Flow and heat transfer in the boundary layer on a continuous moving surface were reported by Tsou et al. [2]. Lin and Shih [3] studied laminar boundary layer heat transfer along static and moving cylinders. Sparrow et al. [4-6] studied local non similar boundary layer equations and their solutions. Seban and Bond [7] studied skin friction and heat transfer characteristics of a laminar boundary layer on a circular cylinder in axial incompressible flow. Fuzi et al. [8] studied laminar natural convective heat transfer from the outer surface of a vertical cylinder. Aziz and $\mathrm{Na}$ [9] analysed laminar natural convection on a vertical cylinder by using perturbation method. Bui and Cebeci [10] studied combined free and forced convection in vertical slender cylinder. Wang and Kleinstruver [11] analysed steady Laminar mixed convection heat transfer on vertical slender cylinders. Agrawal et al. [12] studied effects of MHD free convection and mass transfer on the flow past a vibrating infinite vertical circular cylinder. Dursunkaya and Worek [13] studied diffusion-thermo and thermal-diffusion effects in transient and steady natural convection from vertical surface. Combined forced and natural convection boundary layer flows with Soret and Dufour effects were discussed by Abreu et al. [14]. Ganesan and Loganathan [15-16] studied unsteady free convection flow past a moving vertical cylinder with heat and mass transfer under different physical situations. Takhar et al. [17] studied numerically combined heat and mass transfer effects on moving vertical cylinder in free stream flows. Deka and Paul [18] discussed the transient free convective flow past an infinite vertical cylinder with heat and mass transfer.

If a temperature gradient is applied to a homogeneous binary fluid mixture a concentration gradient is usually established, called Soret effect or thermal diffusion effect. The diffusion flux $\mathbf{i}$ of rarer and lighter component is given by Landau and Lifshitz [19] as

$\mathbf{i}=-\rho \mathrm{D}\left[\nabla \mathrm{C}+\mathrm{k}_{\mathrm{p}} \nabla \mathrm{p}+\mathrm{k}_{\mathrm{T}} \nabla \mathrm{T}\right]$

where $\rho$ is the density of the binary fluid mixture, $k_{p} D$ is the baro-diffusion coefficient, $\mathrm{k}_{\mathrm{T}} \mathrm{D}$ is the thermo-diffusion coefficient and $\mathrm{C}$ is the concentration of rarer and lighter component of the binary fluid mixture. Thermal diffusion describes the tendency for species to diffuse under the influence of a temperature gradient. Sharma and Singh [2021] studied analytically the Soret effect on de-mixing of species in MHD flow of a binary mixture of incompressible viscous fluid between two parallel plates, first taking the plates horizontal and second by taking the plates vertical.

Thermal radiation effect becomes important when the difference between the surface of a body and the surrounding temperature is large. For some industrial applications such as glass production and furnace design, electrical power generation, astrophysical flows, solar power technology which operates at high temperatures, radiation effect can be significant. Hossain and Alim [22] discussed natural convection-radiation interaction on boundary layer flow along a thin vertical cylinder. Raptis et al. [23] studied the effect of thermal radiation on MHD flow. Ganesan and Loganathan [24] studied the radiation and mass transfer effects on flow of an incompressible viscous fluid past a moving vertical cylinder. Gnaneswar Reddy and Bhaskar Reddy [25-26] investigated the thermal radiation and mass transfer effects on 
an unsteady MHD free convection flow of an incompressible viscous fluid past a moving vertical cylinder in different physical situations. Yih [27] discussed the radiation effect on natural convection over a vertical cylinder embedded in a porous media. Chamkha and Ben-Nakhi [28] investigated the MHD mixed convection-radiation interaction along a permeable surface immersed in a porous medium in the presence of Soret and Dufour's effects.

Chemical and metallurgical industries require the study of heat and mass transfer in presence of chemical reaction. The order of the chemical reaction depends on several factors. One of the simplest chemical reactions is the first order reaction in which the rate of reaction is directly proportional to the species concentration. Kandasamy et al. [29] discussed chemical reaction, heat and mass transfer on MHD flow over a vertical stretching surface with heat source and thermal stratification effects. Ibrahim et al. [30] addressed the effect of the chemical reaction and radiation absorption on the unsteady MHD free convection flow past a semi infinite vertical permeable moving plate with heat source and suction. Adrian Postelnicu [31] investigated the influence of chemical reaction on heat and mass transfer by natural convection from vertical surfaces in porous media considering Soret and Dufour effects. Sharma and Kabita Nath [32] studied effects of heat generation, thermal diffusion, magnetic field and chemical reaction by considering a vertical isothermal permeable cylinder moving with a linear velocity in the fluid mixture infinite in extent.

The present paper deals with the effects of magnetic field, thermal diffusion, radiation and chemical reaction in two dimensional steady, laminar, MHD boundary layer flow of an incompressible viscous electrically conducting and chemically reacting binary mixture of fluids past along an axisymmetric, isothermal and moving vertical thin semi infinite impermeable solid cylinder.

The following assumptions concerning the magnetic field and the geometry are made

1. The magnetic field is constant.

2. The magnetic Reynolds number is small so that the induced magnetic field is neglected.

3. The coefficient of electrical conductivity is constant throughout the fluid.

4. The Joule heating of the fluid is neglected.

5. The Hall Effect of magneto- hydrodynamics is neglected.

6. The medium is optically thin with relatively low density.

\section{FORMULATION OF THE PROBLEM}

Consider a steady, laminar, hydro-magnetic, two dimensional boundary layer flow of an electrically conducting and chemically reacting incompressible viscous binary fluid mixture along an axisymmetric, heated and moving vertical thin impermeable semi infinite solid cylinder of radius $\mathrm{R}$. The cylindrical co-ordinates $(x, r)$ are taken such that the axis of the cylinder is parallel to the uniform composite free stream flow U. The origin of the co-ordinate system is at the centre of leading edge of the cylinder. A uniform weak magnetic field of strength $\mathrm{B}_{0}$ is applied normal to the flow direction. The magnetic Reynolds number is assumed to be small so that the induced magnetic field can be neglected. No external electric field is assumed to exist and electric field due to the effect of charge polarization and hence the Hall Effect of magnetohydrodynamics is neglected. In addition, the cylinder moves linearly with uniform velocity about its axis in the same direction as that of the free stream velocity. $\mathrm{T}$ is the temperature of the free stream fluid. The surface of the cylinder is maintained at uniform constant temperature $T_{w}$ while ambient temperature is $T_{\infty}$. It is assumed that $T_{w}>T_{\infty}$. The buoyancy forces arise from both the thermal and mass diffusion processes. Figure 1 shows the physical model and co-ordinate system.

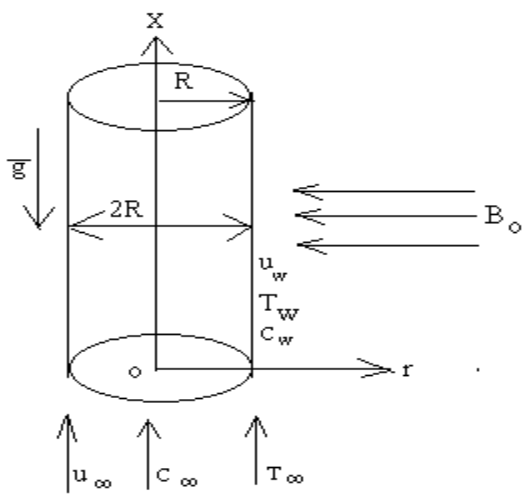

Fig 1: Flow model and physical co-ordinate system

Under the above assumptions and Boussinesq approximation, the dimensional boundary layer equations governing the flow, heat and mass transfer can be expressed as

$$
\begin{aligned}
& \frac{\partial(\mathrm{ru})}{\partial \mathrm{x}}+\frac{\partial(\mathrm{rv})}{\partial \mathrm{r}}=0, \\
& \mathrm{u} \frac{\partial \mathrm{u}}{\partial \mathrm{x}}+\mathrm{v} \frac{\partial \mathrm{u}}{\partial \mathrm{r}}=\frac{\nu}{\mathrm{r}} \frac{\partial}{\partial \mathrm{r}}\left(\mathrm{r} \frac{\partial \mathrm{u}}{\partial \mathrm{r}}\right)+\overline{\mathrm{g}} \beta_{\mathrm{T}}\left(\mathrm{T}-\mathrm{T}_{\infty}\right)+\overline{\mathrm{g}} \beta_{\mathrm{C}}\left(\mathrm{C}-\mathrm{C}_{\infty}\right) \\
& -\frac{\sigma \mathrm{B}_{0}{ }^{2} \mathrm{u}}{\rho},
\end{aligned}
$$

$\mathrm{u} \frac{\partial \mathrm{T}}{\partial \mathrm{x}}+\mathrm{v} \frac{\partial \mathrm{T}}{\partial \mathrm{r}}=\frac{\alpha}{\mathrm{r}} \frac{\partial}{\partial \mathrm{r}}\left(\mathrm{r} \frac{\partial \mathrm{T}}{\partial \mathrm{r}}\right)-\frac{1}{\rho \mathrm{C}_{\mathrm{p}}} \frac{\partial \mathrm{q}_{\mathrm{r}}}{\partial \mathrm{r}}$

and

$$
\begin{aligned}
& \mathrm{u} \frac{\partial \mathrm{C}}{\partial \mathrm{x}}+\mathrm{v} \frac{\partial \mathrm{C}}{\partial \mathrm{r}}= \\
& \mathrm{D}_{\mathrm{m}}\left[\frac{\partial^{2} \mathrm{C}}{\partial \mathrm{r}^{2}}+\frac{1}{\mathrm{r}} \frac{\partial \mathrm{C}}{\partial \mathrm{r}}+\mathrm{S}_{\mathrm{T}}\left\{\left(\mathrm{C}-\mathrm{C}_{\infty}\right)\left(\frac{\partial^{2} \mathrm{~T}}{\partial \mathrm{r}^{2}}+\frac{1}{\mathrm{r}} \frac{\partial \mathrm{T}}{\partial \mathrm{r}}\right)+\left(\frac{\partial \mathrm{C}}{\partial \mathrm{r}}\right)\left(\frac{\partial \mathrm{T}}{\partial \mathrm{r}}\right)\right\}\right] \\
& -\mathrm{k}_{\mathrm{c}}\left(\mathrm{C}-\mathrm{C}_{\infty}\right)
\end{aligned}
$$

together with the boundary conditions

$\mathrm{u}=\mathrm{u}_{\mathrm{w}}, \mathrm{v}=0, \mathrm{~T}=\mathrm{T}_{\mathrm{w}}, \mathrm{C}=\mathrm{C}_{\mathrm{w}}$ when $\mathrm{r}=\mathrm{R}$

and

$\mathrm{u} \rightarrow \mathrm{u}_{\infty}, \mathrm{T} \rightarrow \mathrm{T}_{\infty}$ and $\mathrm{C} \rightarrow \mathrm{C}_{\infty}$ when $\mathrm{r} \rightarrow \infty$

where $r$ is the distance measured from the axis of the cylinder in radial direction; $x$ is the distance measured along the axial direction; $\mathrm{u}$ and $\mathrm{v}$ are the axial and radial velocity components; $\mathrm{C}$ is the concentration of the rarer and lighter component of the binary fluid mixture; $\mathrm{C}_{\mathrm{W}}$ and $\mathrm{C}_{\infty}$ are respectively the concentrations at the surface of the cylinder and at a large distance from the surface of the cylinder; $\mathrm{C}_{\mathrm{p}}$ is 
the specific heat at constant pressure; $\overline{\mathrm{g}}$ is the acceleration due to gravity; $v$ is the kinematic viscosity; $\sigma$ is the electrical conductivity; $\alpha$ is the thermal diffusivity of the fluid; $\mathrm{q}_{\mathrm{r}}$ is the radiation heat flux; $\beta_{\mathrm{T}}$ and $\beta_{\mathrm{C}}$ are coefficients of thermal expansion and mass expansion; $\mathrm{D}_{\mathrm{m}}$ is the diffusion coefficient; $\rho$ is the fluid density; $S_{T}$ is the Soret coefficient and $k_{C}$ is the dimensional chemical reaction parameter respectively. Dimensional boundary layer equations (2) to (7) can be made dimensionless by using the following transformations:

$\xi=\frac{4}{R} \sqrt{\frac{v x}{U}}, \eta=\sqrt{\frac{U}{v x}}\left[\frac{r^{2}-R^{2}}{4 R}\right], U=u_{w}+u_{\infty}$,

$\lambda=\frac{\mathrm{u}_{\mathrm{w}}}{\mathrm{U}}, \quad \psi=\sqrt{\mathrm{vUx}} \operatorname{Rf}(\xi, \eta), \mathrm{u}=\frac{1}{\mathrm{r}} \frac{\partial \psi}{\partial \mathrm{r}}, \mathrm{v}=-\frac{1}{\mathrm{r}} \frac{\partial \psi}{\partial \mathrm{x}}$,

$\theta(\xi, \eta)=\frac{T-T_{\infty}}{T_{w}-T_{\infty}}$ and $\phi(\xi, \eta)=\frac{C-C_{\infty}}{C_{w}-C_{\infty}}$.

For optically thin medium the radiant heat absorption is given by the expression $\frac{\partial \mathrm{q}_{\mathrm{r}}}{\partial \mathrm{z}}=-4 a \sigma^{*}\left(\mathrm{~T}_{\infty}^{4}-\mathrm{T}^{4}\right)$

where $a$ and $\sigma^{*}$ are absorption coefficient and the Stefan Boltzmann constants respectively. It is assumed that temperature differences within the flow are sufficiently small such that $\mathrm{T}^{4}$ can be expanded in a Taylor's series about $\mathrm{T}_{\infty}$ and after rejecting higher order terms

$$
\mathrm{T}^{4}=4 \mathrm{~T}_{\infty}^{3} \mathrm{~T}-3 \mathrm{~T}_{\infty}^{4}
$$

It is found that equation (2) is identically satisfied by the transformations and the equations (3) to (5) reduces to a new set of dimensionless equations given by

$$
\begin{aligned}
& (1+\xi \eta) \mathrm{f}^{\prime \prime}+(\mathrm{f}+\xi) \mathrm{f}^{\prime \prime}+8 \operatorname{Ri}(\theta+\mathrm{N} \phi)-\xi^{2} \mathrm{M}^{2} \mathrm{f}^{\prime}= \\
& \xi\left(\mathrm{f}^{\prime} \frac{\partial \mathrm{f}^{\prime}}{\partial \xi}-\mathrm{f}^{\prime \prime} \frac{\partial \mathrm{f}}{\partial \xi}\right)
\end{aligned}
$$

$$
\begin{aligned}
& (1+\xi \eta) \theta^{\prime \prime}+(\operatorname{Prf}+\xi) \theta^{\prime}-\xi^{2} \mathrm{R}_{\mathrm{d}} \theta=\operatorname{Pr} \xi\left(\mathrm{f}^{\prime} \frac{\partial \theta}{\partial \xi}-\theta^{\prime} \frac{\partial \mathrm{f}}{\partial \xi}\right) \\
& (1+\xi \eta) \phi^{\prime \prime}+(\operatorname{Scf}+\xi) \phi^{\prime}+\mathrm{t}_{\mathrm{d}}(1+\xi \eta) \theta^{\prime \prime} \phi+ \\
& \mathrm{t}_{\mathrm{d}}\left\{(1+\xi \eta) \phi^{\prime}+\xi \phi\right\} \theta^{\prime}+\xi^{2} \gamma \phi=\operatorname{Sc} \xi\left(\mathrm{f}^{\prime} \frac{\partial \phi}{\partial \xi}-\phi^{\prime} \frac{\partial \mathrm{f}}{\partial \xi}\right)
\end{aligned}
$$

together with new boundary conditions:

$$
\mathrm{f}^{\prime}=2 \lambda, \mathrm{f}+\xi \frac{\partial \mathrm{f}}{\partial \xi}=0, \theta=1, \phi=1 \text { when } \eta=0
$$

and

$$
\mathrm{f}^{\prime} \rightarrow 2(1-\lambda), \theta \rightarrow 0, \phi \rightarrow 0 \text { when } \eta \rightarrow \infty
$$

where

$$
\begin{aligned}
& \operatorname{Pr}=\frac{v}{\alpha}, \quad \mathrm{Sc}=\frac{v}{\mathrm{D}_{\mathrm{m}}}, \quad \operatorname{Re}=\frac{\mathrm{UL}}{v}, \mathrm{Gr}_{\mathrm{T}}=\frac{\overline{\mathrm{g}} \beta_{\mathrm{T}}\left(\mathrm{T}_{\mathrm{w}}-\mathrm{T}_{\infty}\right) \mathrm{L}^{3}}{v^{2}}, \\
& \mathrm{Gr}_{\mathrm{C}}=\frac{\overline{\mathrm{g}} \beta_{\mathrm{C}}\left(\mathrm{C}_{\mathrm{w}}-\mathrm{C}_{\infty}\right) \mathrm{L}^{3}}{v^{2}}, \mathrm{Ri}=\frac{\mathrm{Gr}_{\mathrm{T}}}{\operatorname{Re}^{2}}, \mathrm{R}_{\mathrm{d}}=\frac{4 a \sigma^{*} \mathrm{~T}_{\infty} \mathrm{L}^{2}}{\mathrm{k}}, \\
& \mathrm{N}=\frac{\beta_{\mathrm{C}}\left(\mathrm{C}_{\mathrm{w}}-\mathrm{C}_{\infty}\right)}{\beta_{\mathrm{T}}\left(\mathrm{T}_{\mathrm{w}}-\mathrm{T}_{\infty}\right)}, \mathrm{M}^{2}=\frac{\sigma \mathrm{B}_{0}{ }^{2} \mathrm{~L}^{2}}{4 \mu}, \gamma=\frac{\mathrm{k}_{\mathrm{c}} \mathrm{L}^{2}}{4 v}, \\
& \mathrm{t}_{\mathrm{d}}=\mathrm{S}_{\mathrm{T}}\left(\mathrm{T}_{\mathrm{w}}-\mathrm{T}_{\infty}\right) .
\end{aligned}
$$

Here $\xi$ and $\eta$ are transformed coordinates and $\xi$ also represents the curvature parameter; $u_{w}$ is the surface velocity and $\mathrm{u}_{\infty}$ is the free stream velocity respectively; $\mathrm{L}$ is the characteristic length; $\mathrm{k}$ is the thermal conductivity; $\mathrm{Pr}$ is the Prandtl number; $\mathrm{Sc}$ is the Schmidt number; Re is the Reynolds number; $\mathrm{Ri}$ is Richardson number (or the buoyancy parameter); $R_{d}$ is the radiation parameter; $a$ is absorption coefficient; $\sigma^{*}$ is the Stefan Boltzmann constants; $N$ is the ratio of the mass diffusion to the thermal diffusion; $M$ is the magnetic field parameter; $t_{d}$ is the thermal diffusion parameter or Soret number and $\gamma$ is the non-dimensional chemical reaction parameter; $\mathrm{Gr}_{\mathrm{T}}$ and $\mathrm{Gr}_{\mathrm{C}}$ are thermal and mass Grashof numbers respectively. The parameter $\lambda$ is the ratio of the surface velocity $\left(\mathrm{u}_{\mathrm{w}}\right)$ to composite free stream velocity (U) which determines whether the cylinder is moving or stationary. For moving cylinder $0<\lambda<1$ and for stationary cylinder $\lambda=0$. Moreover prime denotes derivative with respect to $\eta$.

\section{METHOD OF SOLUTION}

From mathematical viewpoints, it is much more difficult to solve a system of non-linear and non similar PDEs than ODEs. In general it is very difficult to solve non-linear PDEs, especially by analytical method. In the present problem we have applied combination of both analytical and numerical techniques. For small values of axial distance $\xi$, the partial differential equations (11) to (13) under the boundary conditions (14a) and (14b) are first changed into ordinary differential equations by using regular perturbation expansion procedure and then solved numerically by using Matlab's built in solver bvp4c. By applying this method we have to solve a system of ordinary differential equations instead of the partial differential equations. This approximate method is valid for small values of $\xi$. However, the range of validity of $\xi$ can be increased by using the Shanks transformation. We expand $\mathrm{f}, \theta$ and $\phi$ in powers of $\xi$ as

$$
\begin{aligned}
& \mathrm{f}(\xi, \eta)=\sum_{\mathrm{n}=0}^{\infty} \xi^{\mathrm{n}} \mathrm{f}_{\mathrm{n}}=\mathrm{f}_{0}(\eta)+\xi \mathrm{f}_{1}(\eta)+\xi^{2} \mathrm{f}_{2}(\eta)+\ldots, \\
& \theta(\xi, \eta)=\sum_{\mathrm{n}=0}^{\infty} \xi^{\mathrm{n}} \theta_{\mathrm{n}}=\theta_{0}(\eta)+\xi \theta_{1}(\eta)+\xi^{2} \theta_{2}(\eta)+\ldots
\end{aligned}
$$

and

$$
\phi(\xi, \eta)=\sum_{n=0}^{\infty} \xi^{n} \phi_{n}=\phi_{0}(\eta)+\xi \phi_{1}(\eta)+\xi^{2} \phi_{2}(\eta)+\ldots
$$

Substituting above forms of $f, \theta$ and $\phi$ in equations (11) to (14a) and (14b) and equating the zero ${ }^{\text {th }}$ power of $\xi$ (i.e. for $n$ $=0$ ), after neglecting higher order derivatives with respect to $\xi$, we get

$$
\mathrm{f}_{0}^{\prime \prime}+\mathrm{f}_{0} \mathrm{f}_{0}^{\prime \prime}+8 \operatorname{Ri}\left(\theta_{0}+\mathrm{N} \phi_{0}\right)=0
$$


$\theta_{\mathrm{O}}{ }^{\prime \prime}+\operatorname{Pr}_{\mathrm{o}} \Theta_{\mathrm{O}}{ }^{\prime}=\mathrm{O}$

and

$$
\phi_{0}{ }^{\prime}+\operatorname{Scf}_{0} \phi_{0}{ }^{\prime}=0
$$

with boundary conditions

$$
\mathrm{f}_{0}=0, \mathrm{f}_{0}{ }^{\prime}=2 \lambda, \theta=1, \phi=1 \text { when } \eta=0
$$

and

$$
\mathrm{f}_{0}^{\prime} \rightarrow 2(1-\lambda), \theta_{0} \rightarrow 0, \phi_{0} \rightarrow 0 \text { when } \eta \rightarrow \infty \text {. }
$$

For $\mathrm{n} \geq 1$ the expressions for $\mathrm{f}, \theta$ and $\phi$ are obtained as

follows:

$$
\begin{aligned}
& \mathrm{f}_{\mathrm{n}}^{\prime \prime}+\sum_{\mathrm{m}=0}^{\mathrm{n}} \mathrm{f}_{\mathrm{m}} \mathrm{f}_{\mathrm{n}-\mathrm{m}}^{\prime \prime}+8 R i\left(\theta_{\mathrm{n}}+\mathrm{N} \phi_{\mathrm{n}}\right)-\mathrm{M}^{2} \mathrm{f}_{\mathrm{n}-2}^{\prime}= \\
& \sum_{\mathrm{m}=0}^{\mathrm{n}}(\mathrm{n}-\mathrm{m})\left(\mathrm{f}_{\mathrm{m}}^{\prime} \mathrm{f}_{\mathrm{n}-\mathrm{m}}^{\prime}-\mathrm{f}_{\mathrm{m}}^{\prime \prime} \mathrm{f}_{\mathrm{n}-\mathrm{m}}\right)-\eta \mathrm{f}_{\mathrm{n}-1}^{\prime \prime \prime}-\mathrm{f}_{\mathrm{n}-1}^{\prime \prime}, \\
& \theta_{\mathrm{n}}^{\prime \prime}+\operatorname{Pr} \sum_{\mathrm{m}=0}^{\mathrm{n}} \mathrm{f}_{\mathrm{m}} \theta_{\mathrm{n}-\mathrm{m}}^{\prime}-\mathrm{R}_{\mathrm{d}} \theta_{\mathrm{n}-2}= \\
& \operatorname{Pr} \sum_{\mathrm{m}=0}^{\mathrm{n}}(\mathrm{n}-\mathrm{m})\left(\mathrm{f}_{\mathrm{m}}^{\prime} \theta_{\mathrm{n}-\mathrm{m}}-\theta_{\mathrm{m}}^{\prime} \mathrm{f}_{\mathrm{n}-\mathrm{m}}\right)-\eta \theta_{\mathrm{n}-1}^{\prime \prime}-\theta_{\mathrm{n}-1}^{\prime}, \\
& \phi_{\mathrm{n}}^{\prime \prime}+\operatorname{Sc} \sum_{\mathrm{m}=0}^{\mathrm{n}} \mathrm{f}_{\mathrm{m}} \phi_{\mathrm{n}-\mathrm{m}}^{\prime}+\mathrm{t}_{\mathrm{d}}\left[\sum_{\mathrm{m}=0}^{\mathrm{n}}\left(\theta_{\mathrm{d}}^{\prime \prime} \phi_{\mathrm{n}-\mathrm{m}}\right)+\eta \sum_{\mathrm{m}=0}^{\mathrm{n}-1}\left(\theta^{\prime \prime} \phi_{\mathrm{n}-\mathrm{m}-1}\right)\right] \\
& \left.-\xi^{2} \gamma_{\mathrm{n}-2}=\operatorname{Sc} \sum_{\mathrm{m}=0}^{\mathrm{n}}(\mathrm{n}-\mathrm{m})\left(\mathrm{f}_{\mathrm{m}-\mathrm{m}-\mathrm{m}}^{\prime} \phi_{\mathrm{n}-\phi_{\mathrm{m}}}\right)+\eta \sum_{\mathrm{m}=0}^{\mathrm{n}-1}\left(\theta_{\mathrm{m}-\mathrm{m}}^{\prime} \phi_{\mathrm{n}-\mathrm{m}-1}^{\prime}\right)\right]+\mathrm{t}_{\mathrm{m}=0}^{\mathrm{n}-1}\left(\phi_{\mathrm{m}} \theta_{\mathrm{n}-\mathrm{m}-1}^{\prime}\right) \\
& -\eta \phi_{\mathrm{n}-1}^{\prime \prime}-\phi_{\mathrm{n}-1}^{\prime}
\end{aligned}
$$

with boundary conditions

$$
\mathrm{f}_{\mathrm{n}}=0, \mathrm{f}_{\mathrm{n}}^{\prime}=0, \theta_{\mathrm{n}}=0, \phi_{\mathrm{n}}=0 \quad \text { when } \eta=0
$$

and

$$
\mathrm{f}_{\mathrm{n}}^{\prime} \rightarrow 0, \theta_{\mathrm{n}} \rightarrow 0, \phi_{\mathrm{n}} \rightarrow 0 \text { when } \eta \rightarrow \infty
$$

We have taken $n=4$. Equations (19) to (26b) are solved numerically by employing MATLAB's built in solver bvp4c.

\section{RESULTS AND DISCUSSIONS}

Numerical calculations for axial velocity component, temperature and concentration of the binary fluid mixture have been carried out for various values of the parameters $\xi$, $M, t_{d}, R_{d}$ and $\gamma$. Five different cases are considered:

Case I $\quad: \xi=[0.25,0.5,0.75] ; \mathrm{t}_{\mathrm{d}}=0.3 ; \mathrm{M}=0.02 ; \mathrm{R}_{\mathrm{d}}=2 ; \mathrm{Ri}$ $=1 ; \operatorname{Pr}=0.71 ; \lambda=0.5 ; \mathrm{Sc}=0.9 ; \mathrm{N}=0.5 ; \gamma=1$.

Case II $\quad: \mathrm{M}=[0.02,0.04,0.06] ; \mathrm{t}_{\mathrm{d}}=0.3 ; \xi=0.5 ; \mathrm{R}_{\mathrm{d}}=2$; $\mathrm{Ri}=1 ; \operatorname{Pr}=0.71 ; \lambda=0.5 ; \mathrm{Sc}=0.9 ; \mathrm{N}=0.5 ; \gamma=1$.

Case III : $\mathrm{t}_{\mathrm{d}}=[0,0.3,0.8] ; \mathrm{M}=0.02 ; \mathrm{R}_{\mathrm{d}}=2 ; \mathrm{Ri}=1 ; \mathrm{Pr}=$ $0.71 ; \lambda=0.5 ; \mathrm{Sc}=0.9 ; \mathrm{N}=0.5 ; \xi=0.5 ; \gamma=1$.

Case IV : $\mathrm{R}_{\mathrm{d}}=[0,1.5,3] ; \mathrm{M}=0.02 ; \mathrm{t}_{\mathrm{d}}=0.3 ; \mathrm{Ri}=1 ; \mathrm{Pr}=$ $0.71 ; \lambda=0.5 ; \mathrm{Sc}=0.9 ; \mathrm{N}=0.5 ; \xi=0.5 ; \gamma=1$.

Case V : $\gamma=[0,0.5,1] ; \mathrm{M}=0.02 ; \mathrm{R}_{\mathrm{d}}=2 ; \mathrm{td}=0.3 ; \mathrm{Pr}=$ $0.71 ; \mathrm{Ri}=1 ; \xi=0.5 ; \mathrm{Sc}=0.9 ; \mathrm{N}=0.5 ; \lambda=0.5$
Case I:

The effect of curvature parameter $\xi$ on axial velocity component, temperature and concentration of rarer and lighter component of the fluid are shown in Figures 2-4.

Figure 2 exhibits that with the increase in the value of curvature parameter $\xi$; magnitude of axial velocity component of the binary fluid mixture decreases in the boundary layer region $0<\eta<1$ and reverse effect is noticed in the boundary layer region $1<\eta<4$. Axial velocity component becomes minimum in the region $\eta>4$ for all the values of $\xi$. The maximum axial velocity is attained at about $\eta=0.61$. Figure 3 depicts the effect of curvature parameter $\xi$ on temperature field. It is to be noted that temperature of the fluid is maximum near the surface of the cylinder and minimum at the end of the boundary layer region. It reveals from the Figure 3 that temperature of the binary fluid mixture decreases in the boundary layer region $0<\eta<1.3$ with the increase in the values of curvature parameter $\xi$ and reverse effect is noticed in the region $1.3<\eta<3$. Moreover, temperature of the fluid becomes minimum in the boundary layer region $\eta>3.5$ for all values of $\xi$. Figure 4 depicts the effect of curvature parameter $\xi$ on concentration field. It is observed that with the increase in the values of $\xi$ concentration of the rarer and lighter component of the binary fluid mixture decreases in the region $0<\eta<0.7$ and increases in the region $0.7<\eta<3$.

\section{Case II:}

The effect of magnetic field parameter (M) on axial velocity component, temperature and concentration of rarer and lighter component of the fluid is shown in Figures 5-7.

Figure 5 reveals that the effect of increase in the value of $M$ decreases the axial velocity component of the binary fluid mixture everywhere in the boundary layer region. It is because of the fact that magnetic field results in a damping effect on velocity of the fluid by creating a drag force that opposes the fluid motion. As a result momentum boundary layer thickness is thin in size and hence decreases axial velocity. Maximum axial velocity of the binary fluid mixture is attained at about $\eta$ $=0.5859$. It is observed from the Figure 6 that increasing the value of magnetic field parameter $M$ leads to an increase in the temperature of the binary fluid mixture everywhere in the boundary layer region and thickening the thermal boundary layer size. Figure 7 depicts that as the value of magnetic field parameter increases; concentration of the rarer and lighter component of the binary fluid mixture also increases at any point in the boundary layer region $0<\eta<3.2$.

\section{Case III:}

The effect of thermal diffusion parameter $t_{d}$ on axial velocity component is shown in Figure 8. It is clear from the Figure 8 that increasing the values of $t_{d}$ leads to an increase in the axial velocity component of the binary fluid mixture everywhere in the boundary layer region. Also to be noted that the magnitude of the axial velocity component of the fluid is maximum at about $\eta=0.556$. More axial velocity gradient is noticed in the region $0<\eta<1.5$. Temperature profiles for various values of thermal diffusion parameter $\left(t_{d}\right)$ are shown in the Figures 9. It is seen from the Figure 9 that temperature of the fluid decreases everywhere in the boundary layer region with the increase in the value of thermal diffusion parameter. It means larger the value of $t_{d}$ thinner the temperature boundary layer size, hence decrease in temperature. It is clearly noticed from the Figure10 that increase in the values of $t_{d}$ leads to increase in concentration of the rarer and lighter component of the binary fluid mixture at any point in the 
boundary layer region. More concentration gradient is noticed in the region $0<\eta<2.5$. Moreover, concentration of the rarer and lighter component of the binary fluid mixture is more near the surface of the cylinder and less away from the cylinder.

\section{Case IV:}

The effect of radiation parameter $R_{d}$ on axial velocity component, temperature and concentration of rarer and lighter component of the binary fluid mixture are shown in Figures11-13.

Figure 11 reveals that as the value of radiation parameter increase; magnitude of the axial velocity component of the binary fluid mixture decreases. Maximum value of the axial velocity component is recorded at about $\eta=0.5657$. The axial velocity component is minimum in the region $\eta>3.5$. Variation of axial velocity component is more in the region 0 $<\eta<1$. Figure 12 exhibits that temperature of the binary fluid mixture decreases everywhere in the boundary layer region as the value of radiation parameter increases. This means larger the value of $R_{d}$ thinner the thermal boundary layer size. More variation in the temperature of the binary fluid mixture is noted in the region $0<\eta<1.74$. Figure13 depicts that as the value of radiation parameter increases; concentration of the rarer and lighter component of the binary fluid mixture also increases everywhere in the boundary layer region. Concentration of rarer and lighter component is found to be more near the surface of the cylinder, decreases continuously with increase in the values $\eta$ and minimum at the end of the boundary layer. Variation of concentration of the rarer and lighter component of the fluid is noticed in the region $0<\eta<$ 0.75 .

\section{Case V:}

The effect of chemical reaction parameter $\gamma$ on axial velocity component, temperature and concentration of rarer and lighter component of the binary fluid mixture are shown in Figures 14-16.

Figure14 reveals that with the increase in the value of chemical reaction parameter $\gamma$; magnitude of the axial velocity component of the binary fluid mixture decreases everywhere in the boundary layer region and minimum in the region $\eta>$ 3.6. It is seen from the Figure 15 that an increase in the value of chemical reaction parameter leads to an increase the temperature of the binary fluid mixture everywhere in the boundary layer region. This means the larger the value of $\gamma$, the thicker the thermal boundary layer size, hence increase in the axial velocity of the binary fluid mixture. From Figure16 it is observed that with the increase in the value of chemical reaction parameter; concentration of rarer and lighter component of the binary fluid mixture decreases at any point in the boundary layer region.

It is also clear from the figures 2, 5, 8, 11 and 14 that the axial velocity profiles near the surface of the cylinder exceed the axial velocity at the edge of the boundary layer. It is because of the fact that the buoyancy force that assists the motion acts like a pressure gradient and adds more momentum to the boundary layer which in turn overshoots the axial velocity component of the binary fluid mixture.

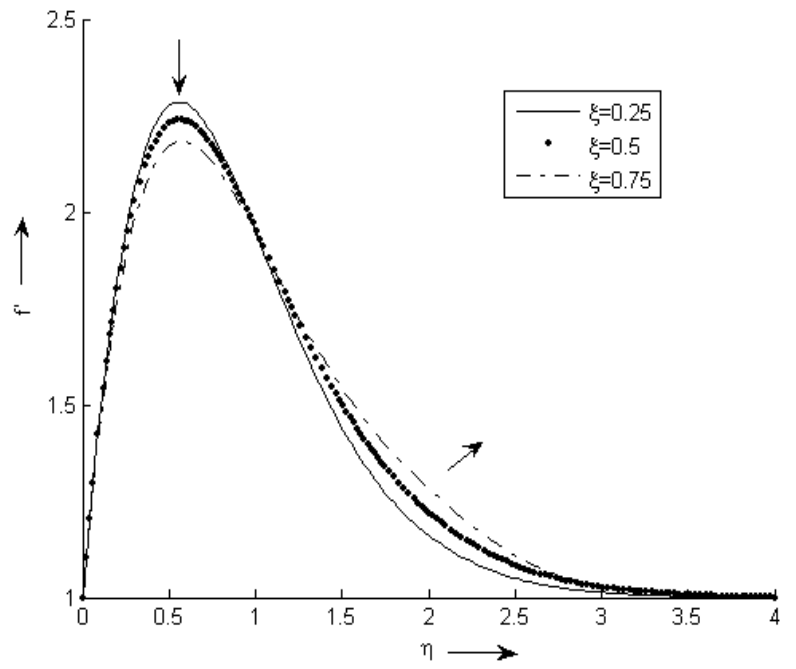

Fig 2: Velocity profiles for various values of $\xi$

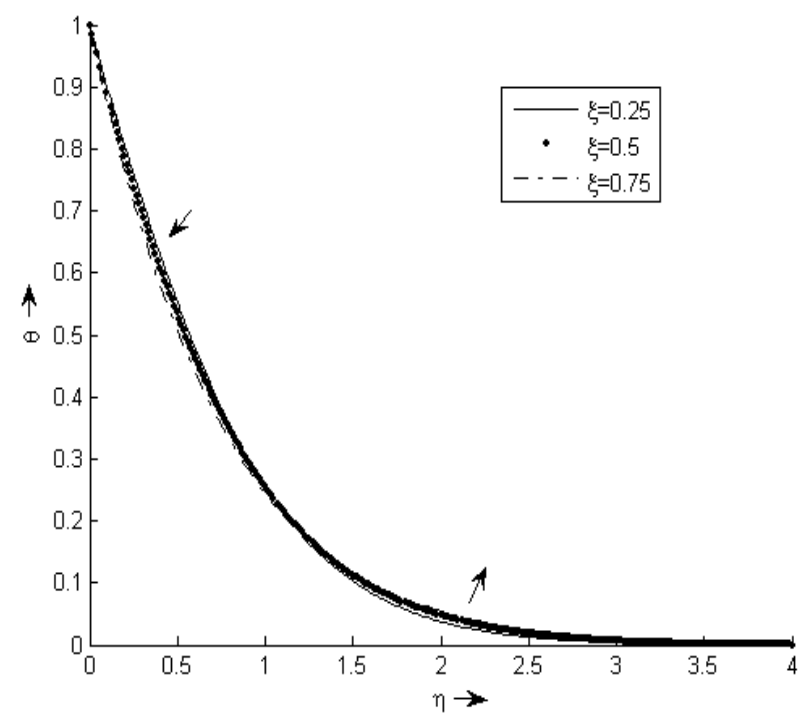

Fig 3: Temperature profiles for various values of $\xi$

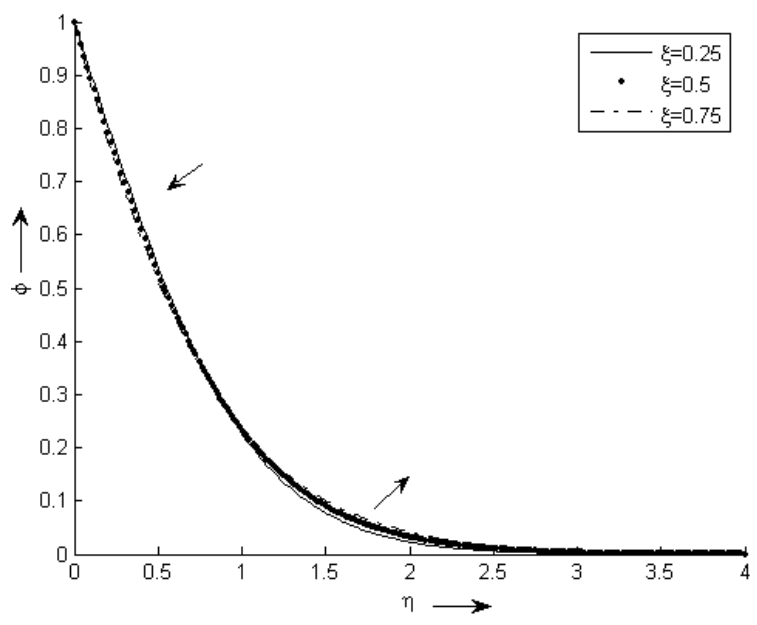

Fig 4: Concentration profiles for various values of $\xi$ 


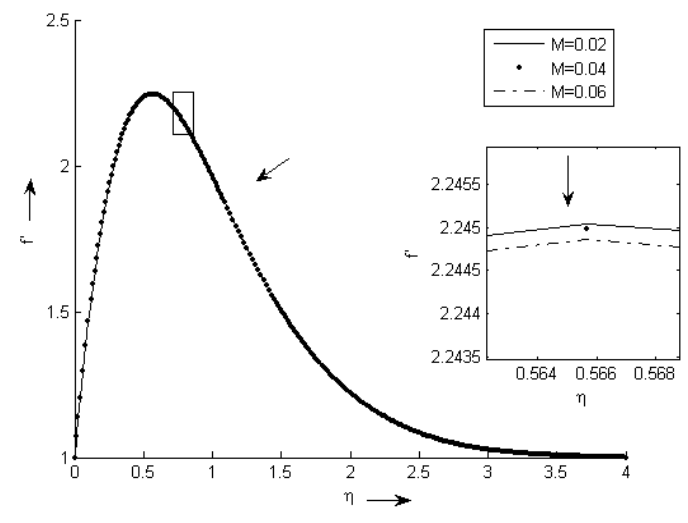

Fig 5: Velocity profiles for various values of $M$

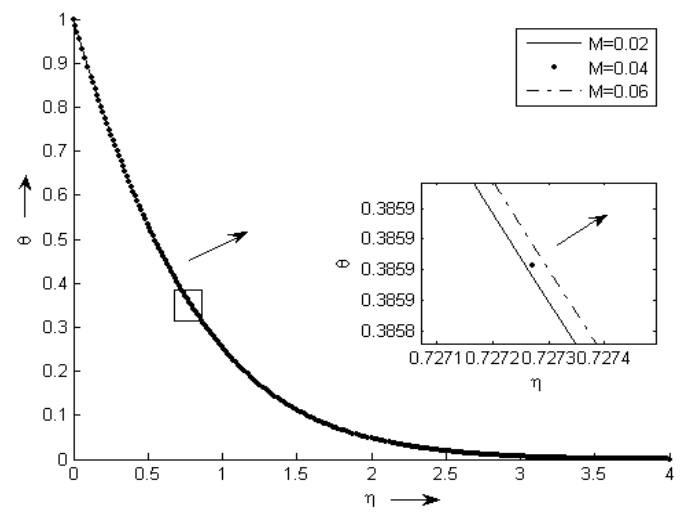

Fig 6: Temperature profiles for various values of $M$

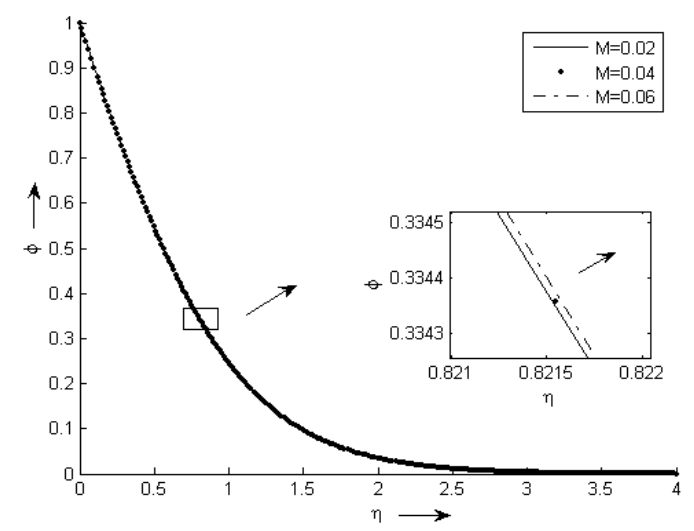

Fig 7: Concentration profiles for various values of $M$

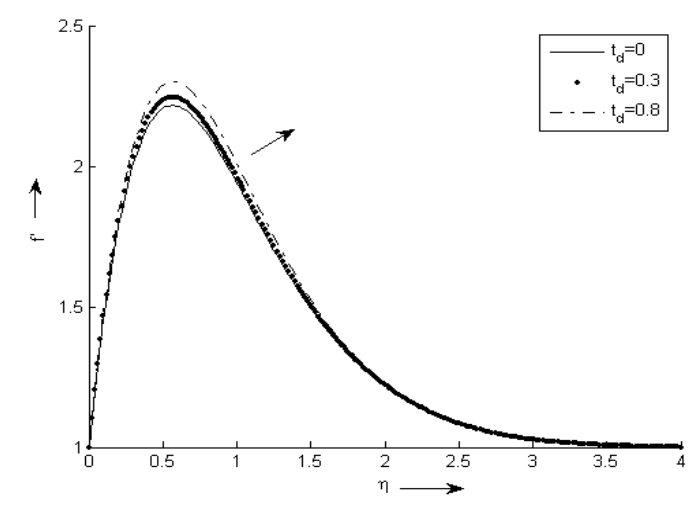

Fig 8: Velocity profiles for various values of $t_{d}$

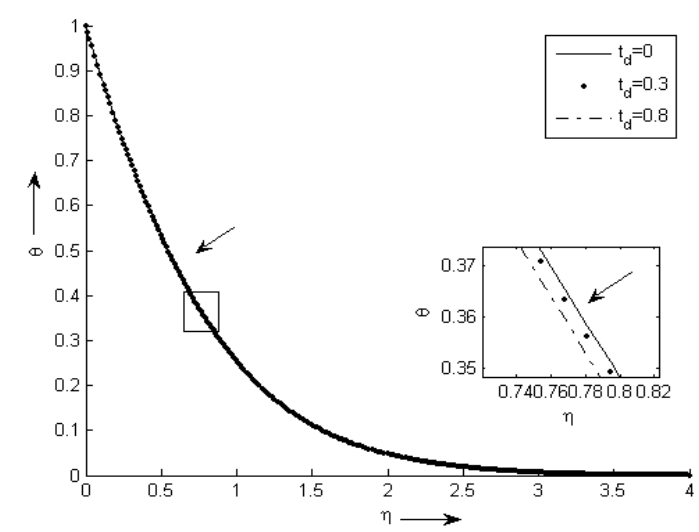

Fig 9: Temperature profiles for various values of $t_{d}$

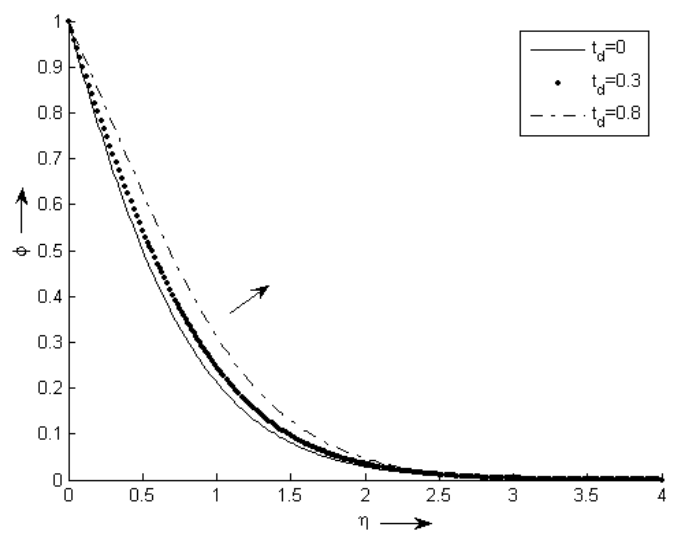

Fig 10: Concentration profiles for various values of $t_{d}$

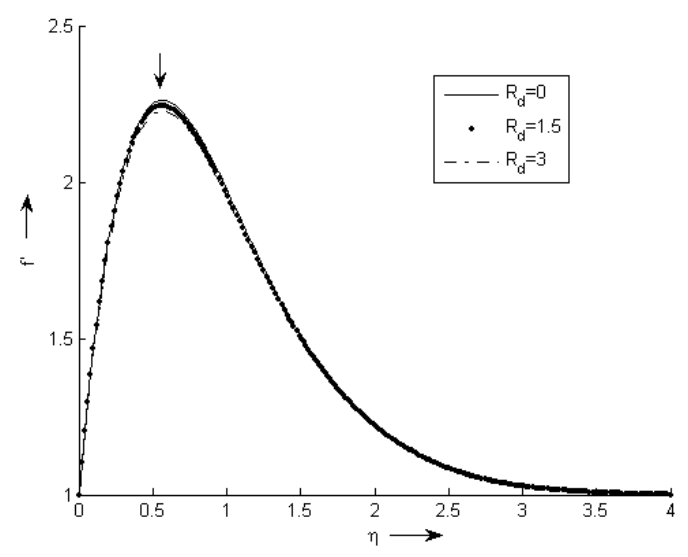

Fig 11: Velocity profiles for various values of $R_{d}$

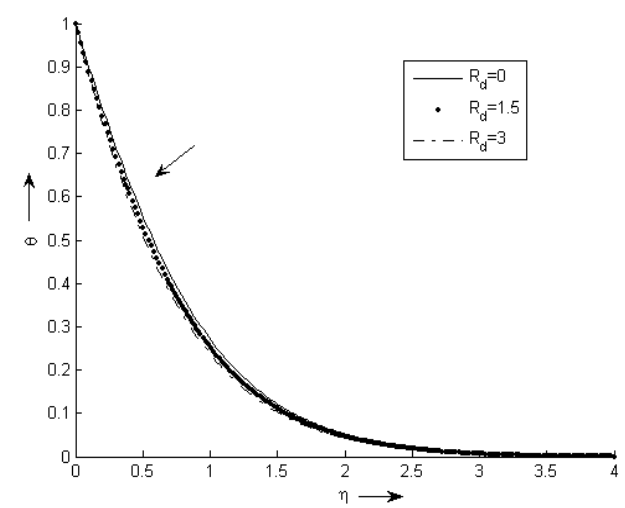

Fig12: Temperature profiles for various values of $\mathbf{R}_{d}$ 


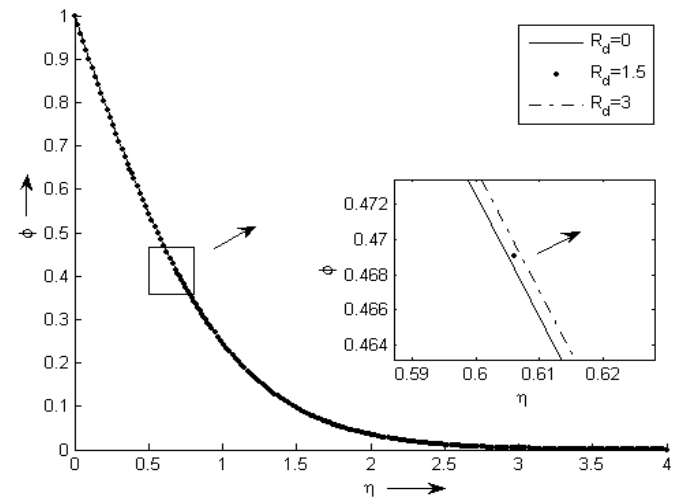

Fig 13: Concentration profiles for various values of $\mathbf{R}_{d}$

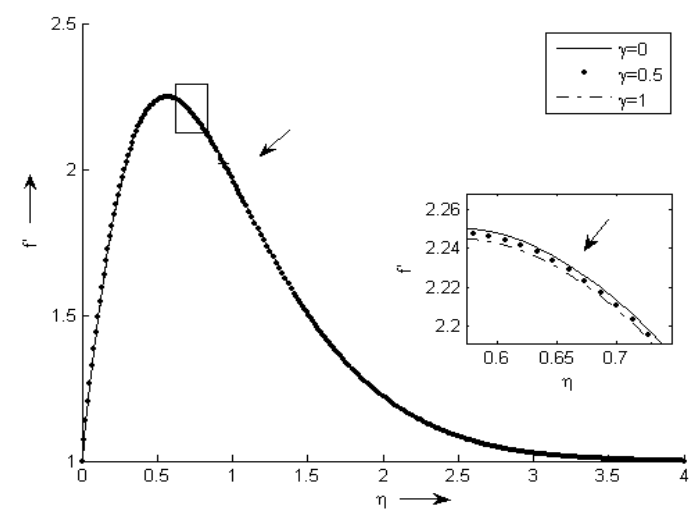

Fig 14: Velocity profiles for various values of $\gamma$

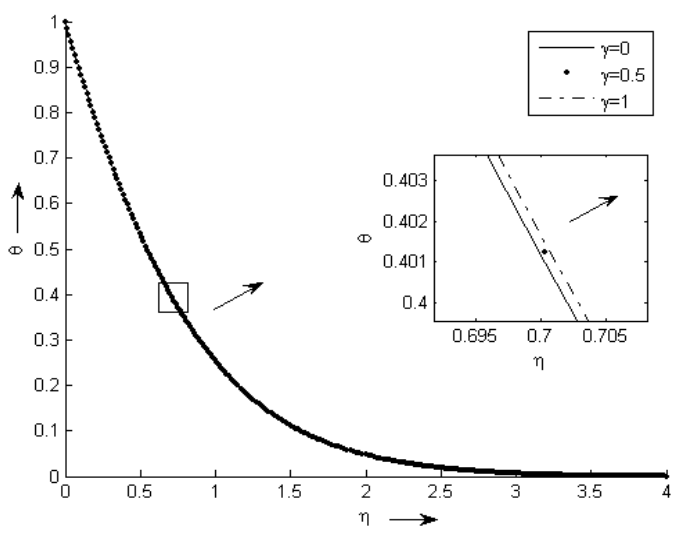

Fig 15: Temperature profiles for various values of $\gamma$

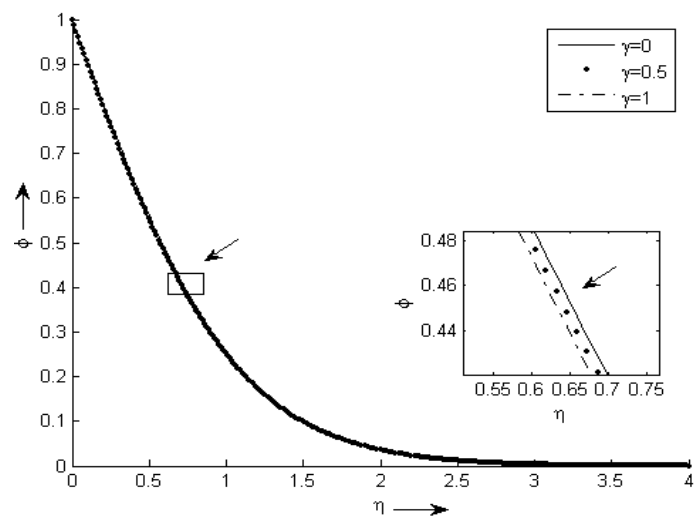

Fig 16: Concentration profiles for various values of $\gamma$

\section{CONCLUSION}

The conclusions of this study are as follows:

$>$ The effect of increase in the value of curvature parameter $\xi$ is to decrease the magnitude of the axial velocity component, temperature and concentration of the binary fluid mixture near the surface of the cylinder and to increase them at the end of the boundary layer.

$>$ The effect of increase in value of magnetic field parameter (M) is to decrease axial velocity component and to increase temperature and concentration of the binary fluid mixture in the boundary layer.

$>$ The effect of increase in the value of thermal diffusion parameter $\left(t_{d}\right)$ is to increase the axial velocity component and concentration of the rarer and lighter component of the binary fluid mixture near the surface of the cylinder and to decrease the temperature of the fluid everywhere in the boundary layer.

$>$ The effect of increase in the value of radiation parameter $\left(R_{d}\right)$ is to decrease the axial velocity component and temperature of the fluid and to increase the concentration of the binary fluid mixture everywhere in the boundary layer.

$>$ The effect of increase in the value of chemical reaction parameter $(\gamma)$ is to decrease the axial velocity component and concentration of the binary fluid mixture and to increase temperature of the fluid everywhere in the boundary layer.

$>$ Axial velocity component, temperature and concentration of rarer and lighter component of the binary fluid mixture are more near the surface of the cylinder and less at the end of the boundary layer.

In this paper we have discussed the effects of magnetic field, thermal diffusion, radiation and chemical reaction on an impermeable, isothermal moving thin solid cylinder. So, further investigation of the problem can be done by considering suction and injection of the fluid into the cylinder. Moreover, heat generation or absorption case also can be considered

\section{ACKNOWLEDGMENTS}

The second author is thankful to Nagaland Government for providing financial support and to Dibrugarh University for providing all academic facilities during the preparation of this research paper.

\section{REFERENCES}

[1] Sakiadis, B.C. (1961). Boundary-layer behavior on continuous solid surfaces: I. Boundary-layer equations for two dimensional and axisymmetric flows, AIChE Journal, 7(1), 26-28.

[2] Tsou, F. K., Sparrow, E. M., and Goldstein, R. J. (1967). Flow and heat transfer in the boundary layer on a continuous moving surface, International Journal of Heat and Mass Transfer, 10(2), 219-235

[3] Lin, H. T., and Shih, Y. P. (1980). Laminar boundary layer heat transfer along static and moving cylinders, Journal of the Chinese Institute of Engineers, 3(1), 73-79.

[4] Sparrow, E. M., Quack, H., and Boerner, C. J. (1970). Local non similarity boundary layer solutions, AIAA Journal, 8(11), 1936-1942. 
[5] Sparrow, E. M., and Yu, H. S. (1971). Local non similarity thermal boundary layer solutions, Journal of Heat Transfer, 93(4), 328-334.

[6] Minkowcyz, W. J., and Sparrow, E. M. (1974). Local non-similar solutions for natural convection on a vertical cylinder, Journal of Heat Transfer 96(2), 178-183.

[7] Seban, R.A., and Bond, R. (1951). Skin friction and heat transfer characteristics of a laminar boundary layer on a circular cylinder in axial incompressible flow, Journal of Aeronautical Science, 18(10), 671-675.

[8] Fuzi, T., and Uehara, H. (1970). Laminar natural convective heat transfer from the outer surface of a vertical cylinder, International Journal of Heat and Mass Transfer, 13(3), 607-615.

[9] Aziz, A., and Na, T.Y. (1982). Improved perturbation solutions for laminar natural convection on a vertical cylinder, Wärme-und Stoffübertragung, 16(2), 83-87.

[10] Bui, M. N. and Cebeci, T. (1985). Combined free and forced convection in vertical slender cylinder, Journal of Heat Transfer, 107(2), 476-478

[11] Wang, T. Y., and Kleinstruver, C. (1989). General analysis of steady Laminar mixed convection heat transfer on vertical slender cylinders, Journal of Heat Transfer, 111(2), 393-398.

[12] Agrawal, A. K., Kishor, B., and Raptis, A. (1989). Effects of MHD free convection and mass transfer on the flow past a vibrating infinite vertical circular cylinder, Journal of Heat and Mass Transfer, 24(4), 243-250.

[13] Dursunkaya, Z., and Worek, W. M. (1992). Diffusionthermo and thermal-diffusion effects in transient and steady natural convection from vertical surface, International Journal of Heat and Mass Transfer, 35(8) 2060-2065.

[14] Abreu, C.R.A., Alfradique, M.F.A., and Silva Telles, A. (2006). Boundary layer flows with Dufour and Soret effects: I: Forced and natural convection, Chemical Engineering Science, 61(13), 4282-4289.

[15] Ganesan, P., and Langanathan, P. (2001). Unsteady free convection flow over a moving vertical cylinder with heat and mass transfer, Journal of Heat and Mass Transfer, 37(1), 59-65.

[16] Ganesan, P., and Langanathan, P. (2001). Effects of mass transfer and flow past a moving vertical cylinder with constant heat flux, Acta Mechanica, 150, (3-4), 179-190.

[17] Takhar, H. S, Chamkha, A. J., and Nath, G. (2000). Combined heat and mass transfer along a vertical moving cylinder with a free stream, Heat and Mass transfer, 36(3), 237-246.

[18] Deka, Rudra Kanta, and Paul, Ashish. (2011). Transient free convective flow past an infinite vertical cylinder with heat and mass transfer, Applied Mathematical Sciences, 5(79), 3903-3916.

[19] Landau, L. D., and Lifshitz, E. M. (1960). Electrodynamics of Continuous Media, Pergamon Press, New York.

[20] Sharma, B. R., and Singh, R. N. (2004). Soret effect in generalized MHD Couette flow of a binary mixture, Bull Cal Math Soc., 96, 367-374.
[21] Sharma, B. R., and Singh, R. N. (2007). Soret effect due to natural convection between heated vertical plates in a horizontal small magnetic field, Ultra Science, 19, $97-$ 106.

[22] Hossain, M. A., and Alim, M. A. (1997). Natural Convection-Radiation Interaction on Boundary Layer Flow along a Thin Vertical Cylinder, Heat and Mass Transfer, 32(6), 515-520.

[23] Raptis A., Perdikis, C., and Takhar, H. S. (2004). Effect of thermal radiation on MHD flow, Applied Mathematics and Computation, 153(3), 645-649.

[24] Ganesan, P., and Langanathan, P. (2002). Radiation and mass transfer effects on flow of an incompressible viscous fluid past a moving vertical cylinder, International Journal of Heat and Mass Transfer, 45(21), 4281-4288.

[25] Ganeswar Reddy, M., and Bhaskar Reddy, N. (2009). Thermal Radiation and mass transfer effects on MHD free convective flow past a vertical cylinder with variable surface temperature and concentration, Journal of navel and architectural engineering, 6(1), 1-24.

[26] Ganeswar Reddy, M., and Bhaskar Reddy, N. (2009). Radiation and mass transfer effects on unsteady MHD free convective flow of an incompressible viscous fluid past a moving vertical cylinder, Theoretical applied Mechanics, 36 (3), 239-260.

[27] Yih, K. A. (1999). Radiation effect on natural convection over a vertical cylinder embedded in porous media, International Communications in Heat and Mass Transfer, 26(2), 259-267.

[28] Chamkha, A. J., and Ben-Nakhi, A. (2008). MHD mixed convection-radiation interaction along a permeable surface immersed in a porous medium in the presence of Soret and Dufour's Effects, Heat and Mass Transfer, 44 (7), 845-856.

[29] Kandasami, R., Periasami, K., and Prabhu Sivagnana, K. K. (2005). Chemical reaction, heat and mass transfer on MHD flow over a vertical stretching surface with heat source and thermal stratification effects, International Journal of Heat and Mass Transfer., 48(21-22), 45574561.

[30] Ibrahim, F. S., Elaiw, A. M., and Bakr, A. A. (2008), Effect of the chemical reaction and radiation absorption on the unsteady MHD free convection flow past a semi infinite vertical permeable moving plate with heat source and suction., Communications in Nonlinear Science and Numerical Simulation, 13 (6), 1056-1066.

[31] Postelnicu, Adrian. (2007). Influence of chemical reaction on heat and mass transfer by natural convection from vertical surfaces in porous media considering Soret and Dufour effects, Heat and Mass Transfer, 43(6), 595602.

[32] Sharma, B. R., and Nath, Kabita. (2013), Effects of Heat Generation, Thermal Diffusion, Magnetic Field and Chemical Reaction on De-mixing of a Binary Fluid Mixture, Journal of Applied Mathematics and Fluid Mechanics, 5(1), 23-31. 